Hydraulic Analysis of Unsteady Flow in Pipe Networks 


\section{Hydraulic Analysis of Unsteady Flow in Pipe Networks}

\section{J. A. FOX}

Reader in Civil Engineering

University of Leeds 
(C) J. A. Fox 1977

Softcover reprint of the hardcover 1st edition 1977 978-0-333-19142-2

All rights reserved. No part of this publication may

be reproduced or transmitted, in any form or by

any means, without permission

First published 1977 by

THE MACMILLAN PRESS LTD

London and Basingstoke

Associated companies in New York Dublin

Melbourne Johannesburg and Madras

ISBN 978-1-349-02792-7 ISBN 978-1-349-02790-3 (eBook)

DOI 10.1007/978-1-349-02790-3

This book is sold subject to the standard conditions of the Net Book Agreement 


\section{Contents}

Preface ix

Notation xi

1 Simple waterhammer theory 1

1.1 Introduction 1

1.2 Rigid pipe-incompressible fluid theory 2

1.3 Sudden valve opening at the downstream end of a pipeline 4

1.4 Slow valve closure 6

1.5 Distensible pipe-elastic fluid theory 9

$\begin{array}{lr}1.6 & \text { Instantaneous valve closure } \\ 1.7 & 10\end{array}$

$\begin{array}{lll}1.7 & \text { Separation } & 16\end{array}$

1.8 The calculation of the magnitude of the transient caused by complete instantaneous valve closure at the

1.9 Pressure rise caused by instantaneous valve closure 21

1.10 Sudden valve closure 21

2 Analytic and graphical methods 23

2.1 Introduction 23

2.2 Analytic methods of solution 23

2.3 Stepwise valve closures at pipe period intervals 23

2.4 The Allievi interlocking equations 25

2.5 The Schnyder-Bergeron graphical method 36

3 Boundary conditions for use with graphical methods

3.1 Introduction $\quad 55$

3.2 Pumps 55

3.3 Four quadrant pump operation $\quad 60$

3.4 Surge tanks 62

3.5 Types of surge tanks 63

3.6 Transient analysis of surge tanks 65

3.7 Mass oscillation of surge tanks 66

3.8 Pressurised surge tanks or air vessels $\quad 68$

3.9 Methods of integrating the surge tank equations $\quad 70$ 
4.1 Introduction 72

4.2 Method of deriving the characteristic forms of the waterhammer equations

4.3 The characteristic forms of the waterhammer equations 77

4.4 The zone of influence and the domain of dependency 78

$\begin{array}{ll}\text { 4.5 The zone of quiet } & 79\end{array}$

4.6 The integration of the characteristic equations $\quad 79$

4.7 Boundary conditions $\quad 81$

4.8 The method of the regular rectangular grid 82

4.9 Other finite difference methods 85

5 Variable parameters in unsteady flow 87

$\begin{array}{ll}5.1 & \text { Variation of wavespeed } \\ 5.2 & 87\end{array}$

5.2 Gas evolution 88

5.3 The magnitude of variable wavespeed and the inclusion of gas release 90

5.4 The use of the variable wavespeed equation $\quad 94$

$\begin{array}{lll}5.5 & \text { Vaporous cavitation } & 94\end{array}$

5.6 Calculation of friction $\quad 95$

5.7 The use of variable $f$ values $\quad 96$

5.8 Interpolation 97

5.9 The calculation of the free bubble content 98

5.10 Evaluation of velocities and potential heads at internal points in a pipe length 99

6 Boundary conditions: pumps 100

$\begin{array}{ll}6.1 \text { Introduction } & 100\end{array}$

6.2 Pumps equipped with a nonreturn valve 100

6.3 The derivation of the pump's characteristic equation 101

6.4 Dynamometer/turbine operation of a pump with forward flow

$\begin{array}{lll}6.5 & \text { Pump efficiency } & 105\end{array}$

$\begin{array}{lll}\text { 6.6 Pump power } & 105\end{array}$

6.7 Pump start up 106

6.8 Pump run down 107

6.9 The in-line pump boundary condition 108

6.10 Suction well pumps 110

6.11 Four quadrant pump operation 111

6.12 The use of the Suter curves 118

6.13 Pump run up to steady speed of pumping $\quad 120$

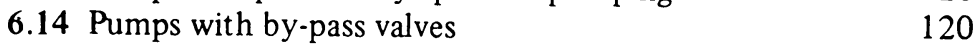

$\begin{array}{ll}6.15 \text { Pump stations } & 121\end{array}$

6.16 Surge suppression of transients generated by pump trip 124

$\begin{array}{ll}6.17 \text { Line pack and attenuation } & 127\end{array}$

$\begin{array}{ll}6.18 \text { Lock in } & 128\end{array}$ 
7 Other boundary conditions 130

$\begin{array}{lll}7.1 \text { Junctions } & 130\end{array}$

$\begin{array}{llr}7.2 & \text { Joints } & 132\end{array}$

$\begin{array}{lll}7.3 \text { Air vessels } & 134\end{array}$

7.4 The motorised valve 136

$\begin{array}{lll}7.5 & \text { Servocontrolled valves } & 142\end{array}$

$\begin{array}{lll}7.6 & \text { Reservoirs } & 144\end{array}$

$\begin{array}{lll}7.7 & \text { Bends } & 146\end{array}$

8 Unsteady flow in gas networks 147

8.1 Introduction 147

8.2 Basic equations 147

8.3 Characteristic equations 149

8.4 The value of $1 \quad 150$

8.5 Boundary conditions 154

9 Impedance methods of pipeline analysis 155

9.1 Introduction 155

9.2 The analogy between electrical and hydraulic impedance 156

9.3 The linearisation of the waterhammer equations 157

9.4 The solution of the linearised waterhammer equations 160

$\begin{array}{ll}\text { 9.5 The evaluation of } \gamma & 162\end{array}$

9.6 The impedance concept 164

9.7 Receiving and sending ends 165

9.8 The equation of impedance 165

9.9 Boundary conditions 167

9.10 The impedance of a network 170

9.11 Harmonic analysis 172

9.12 The forcing oscillation 173

9.13 The oscillating valve 174

9.14 A network in which resonance can be excited by forcing oscillations located at different points in the network $\quad 176$

10 Unsteady flow in open channels 177

10.1 Introduction 177

10.2 The equations of unsteady flow in open channels 178

10.3 The characteristic forms of the open channel equations 181

10.4 The travelling surge 192

10.5 The profile of a free surface flow when a travelling surge is present

10.6 The method of analysis of an unsteady free surface flow in which travelling surges are present 195

10.7 Other methods of analysis 199 
viii

Contents

11 Global programming 201

$\begin{array}{lll}11.1 & \text { Introduction } & 201\end{array}$

11.2 The route or link method of global programming 201

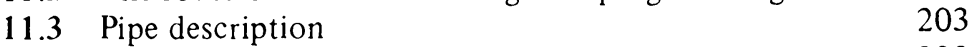

11.4 Longitudinal profiles 203

$\begin{array}{lll}11.5 & \text { Upstream reservoirs } & 204\end{array}$

11.6 Downstream reservoirs 204

11.7 Pump description 204

11.8 Pipe longitudinal profiles at $\Delta x$ intervals 205

11.9 Calls of procedures $\quad 205$

11.10 Time level scanning 206

$\begin{array}{ll}\text { References } & 207\end{array}$

Bibliography 209

$\begin{array}{ll}\text { Index } & 211\end{array}$ 


\section{Preface}

The reader may be interested to know how this book came to be written.

The author has always found the subject of unsteady flow of great interest and throughout his career has studied it with special application. As a consequence most of his research effort has been in this area and he has guided many of his Ph.D. students into this topic also.

In 1969 an engineer from a local Consulting Engineer's office approached him requesting information concerning surge analysis methods which could take into account variations in wavespeeds caused by free bubbles in the fluid. At that moment in time the author had already developed a computer program which could analyse surge in simple rising mains but had not included this wavespeed effect. The effect was soon incorporated into the program and it was used to analyse a main which had a history of bursting to decide what was the main cause of the bursts. At the same time, unknown to the author, one of his own ex-Ph.D. students had been employed to take measurements of the pressure history of the main. When the analytic results were compared with the measured results it was found that agreement was extremely good, the only error of significance being in the timing of the pressure peaks. The actual magnitudes of the maximum and minimum pressures were excellently predicted.

Upon seeing these results the author and the engineer from the Consulting Engineer's office, Bryan Smith, decided to open an office, Hydraulic Analysis Ltd, Leeds, which would routinely undertake the analysis of proposed or existing systems. This venture turned out quite successfully and with the passage of time the firm has been called upon to analyse more and more complex systems, ranging from simple rising mains delivering sewage to a sewage works, to undersea oil pipelines such as that of the Forties field in the North Sea. The firm has been called in to analyse water supply networks for various authorities throughout the world, oil pipelines in the Middle East, most of the pipelines built or proposed for the North Sea, water injection schemes to improve oil delivery from underground strata, pipe networks in Condeeps and other complex networks such as those found in oil refineries and gas liquefaction plants. The firm has had to grow to handle this work, taking in a computer specialist, Andrew Keech, 
as a partner and employing more staff.

Throughout this period it has been necessary to develop the original program and now it has reached a considerable level of sophistication.

As an academic, the author feels that the essential material in this program should be published and so he decided to write this book. It is not possible to include within the confines of one book all of the material that has gone into the program; there are many facilities which have not been included but the main material on which the program is based has been described.

The author would like to warn the reader that he has not tried to write the definitive book of waterhammer. It probably could not be written at present as the subject is still undergoing rapid development. Even so, this book is an idiosyncratic view of waterhammer and many people who have contributed greatly to the subject may feel slighted by the omission of their material or by the failure even to mention its existence. The author would like to apologise to such people and would plead, in advance, the limitations of space.

The book is idiosyncratic in other ways, techniques of finite difference integration such as those due to Lax, Wendroff and coauthors have only been given passing mention and no mention at all has been made of what the author believes is a potential technique for the future - the finite element method. However, he has demonstrated, to his own satisfaction at least, the complete adequacy of the method of characteristics and offers this as partial justification for his limited presentation of a very large, very complex subject.

Leeds, 1976

J. A.F. 


\section{Notation}

Throughout this book, symbols are defined wherever they are used and these are listed below. However, variables of local interests only are not included in this list but are defined in the text.

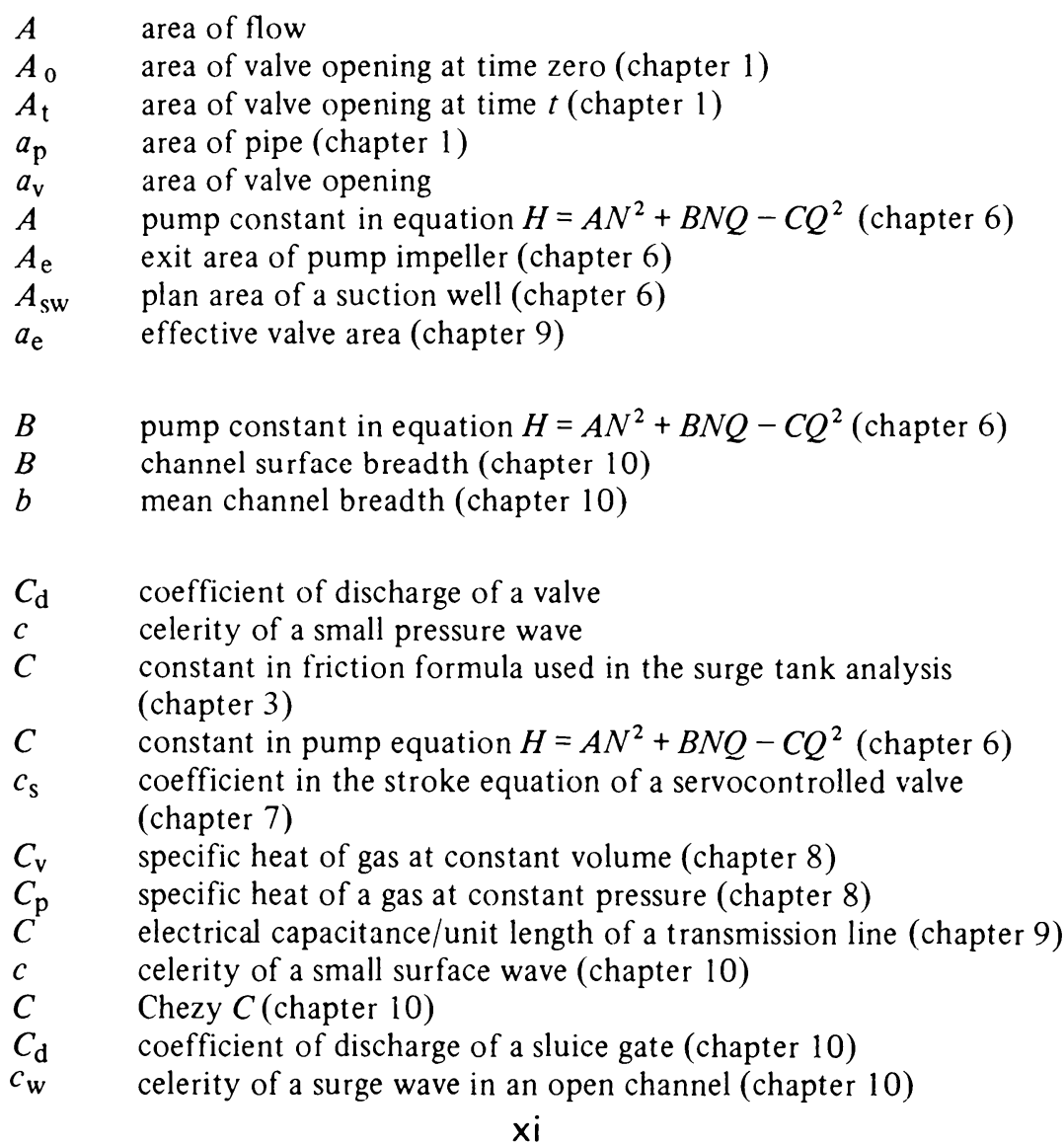


$d t \quad$ time increment (infinitesimal)

$d x$ distance increment (infinitesimal)

$d p \quad$ pressure increment (infinitesimal)

$d \rho$ density increment (infinitesimal)

$d v \quad$ velocity increment (infinitesimal)

d pipe diameter

$D \quad$ pump impeller diameter

$D_{\text {e }} \quad$ constant in the pump efficiency equation

$d_{\text {sw }} \quad$ depth in a suction well

$d_{\mathrm{t}} \quad$ internal diameter of an air vessel

$E \quad$ Young modulus of elasticity

$E \quad$ pump efficiency (chapter 3 )

$E_{\mathrm{e}} \quad$ constant in the pump efficiency equation (chapter 3 )

$e \quad$ internal energy of gas/unit mass (chapter 8)

$\left.\begin{array}{l}E_{1} \\ E_{2}\end{array}\right\} \quad$ constants in the characteristic forms of the unsteady gas equations $E_{3} \quad$ as defined in text (chapter 8)

E $\quad g(j-i)($ chapter 10$)$

$f \quad$ Darcy $f$ in the Darcy formula

$h f=\frac{f L V^{2}}{2 g m}($ as defined in text $)$

$f_{\mathrm{h}} \quad$ hoop stress in pipe wall

$f$ 'function of' and wave height when wave is travelling downstream (chapter 2)

$F$ 'function of' and wave height when wave is travelling upstream (chapter 2)

$F_{\mathrm{e}} \quad$ constant in the pump efficiency equation

$F \quad$ in chapter 8 , the force acting upon the fluid/unit length of pipe

$f \quad$ frequency of applied head oscillation (chapter 9)

$F_{\mathrm{n}} \quad$ Froude number (based on absolute velocity) (chapter 10)

$g \quad$ intensity of the local gravitational field throughout the text

Gr gradient of the pump's speed $\sim$ time rundown curve (chapter 6 )

$h \quad$ potential head - the sum of local pressure head and elevation of the point above an arbitrary datum.

$h_{\mathrm{f}} \quad$ head lost due to friction

$h_{\mathrm{s}} \quad$ sometimes static head, sometimes head at point $S$, according to context

$h_{\mathrm{n}} \quad$ head immediately upstream of a valve or nozzle.

$h_{\mathrm{i}} \quad$ potential head change caused by momentum changes (note $\left.p_{\mathrm{i}}=w h_{\mathrm{i}}\right)$ 
$h_{\text {air }} \quad$ pressure head of air in an air vessel expressed as height of the equivalent liquid column (chapter 3 )

$h_{\mathrm{a}} \quad$ atmospheric pressure head

$h_{\mathrm{p}} \quad$ height of the base of an air vessel above the pipe centre line

$h_{\mathrm{w}} \quad$ as $h_{\text {air }}$ above (chapter 7)

$h_{\mathrm{tr}} \quad$ head sensed by a pressure transducer controlling a servo-operated valve

$h_{\text {crit }} \quad$ critical head at which a servo-operated valve will start to move.

$\bar{h} \quad$ steady state head (chapter 9)

$h^{\prime} \quad$ unsteady head component (chapter 9)

$H \quad$ amplitude of pressure head wave (chapter 9)

$h_{\mathrm{sp}} \quad$ height of the reservoir surface above the spillway crest (chapter 10)

$h_{\mathrm{w}} \quad$ the height of a wave crest above channel bed level (chapter 10)

$I \quad$ inertia of the rotating parts of a pump and motor set (chapter 6)

$i \quad$ electrical current (chapter 9)

$i \quad \sqrt{-1}$ (chapter 9) (see context)

$i \quad$ channel bed slope - taken positively downwards (chapter 10)

$j \quad$ frictional head loss/unit weight of fluid/unit length of channel (chapter 10)

$K \quad$ constant in valve loss formula $h_{\mathrm{f}}=K \frac{v^{2}}{2 g}$

$$
K=\frac{4 f L}{d}+k(\text { chapter } 1 \text { and chapter } 5)
$$

$K \quad$ bulk modulus of liquid

$k \quad$ constant, sometimes describing local losses,

i.e. $h_{\mathrm{L}}=k \frac{v^{2}}{2 g}$ (due to bends, junctions etc)

In chapter 1 also used: $k=\frac{v_{0} L h_{\mathrm{s}}}{g T}$

$k \quad$ constant in head $\sim q$ equation $h=k q^{2}$,

i.e. the friction formula used in the Schnyder-Bergeron method (chapter 5)

$k$ mean height of pipe roughnesses in the Colebrook-White formula

$k_{\mathrm{r}} \quad$ pump impeller head loss coefficient (chapter 6)

$k_{\mathrm{v}} \quad$ pump volute head loss coefficient (chapter 6)

$k \quad$ spillway constant (chapter 10)

$L \quad$ length, usually pipe length $L$

$L$ constant in the development of the characteristic form of the differential equations of waterhammer (chapter 7)

$l_{\mathrm{t}} \quad$ internal height of an air vessel (chapter 7)

$L \quad$ electrical inductance/unit length of a transmission line (chapter 9) 


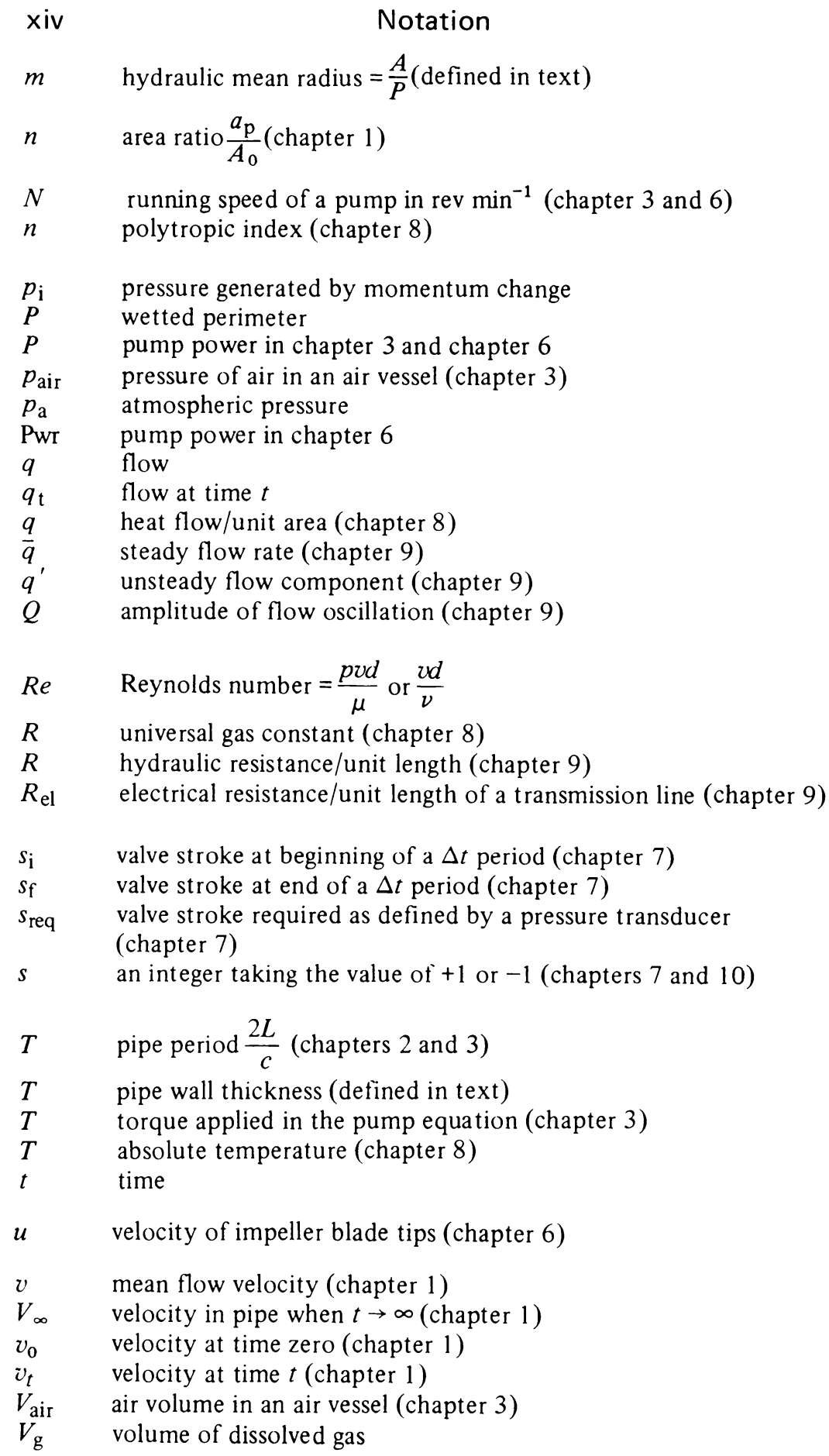


$V_{\mathrm{W}} \quad$ velocity of whirl at exit from a pump impeller (chapter 6)

$V_{\mathrm{r}} \quad$ relative velocity at exit from a pump impeller (chapter 6)

$V \quad$ absolute velocity at exit from a pump impeller (chapter 6)

$V_{\mathrm{f}} \quad$ velocity of flow at exit from a pump impeller (Chapter 6)

$V \quad$ electrical voltage (chapter 9)

$V_{\mathrm{w}} \quad$ velocity of a surge wave in an open channel (Chapter 10)

$w \quad$ weight density of fluid

$W_{H} \quad$ dimensionless heat parameter in the head Suter curve (chapter 6)

$W_{\mathrm{T}}$ dimensionless torque parameter in the torque Suter curve (chapter 6)

$x \quad$ distance along pipeline

$X \quad$ distance along pipeline

$z \quad$ elevation of the pipe centre line above datum

$z \quad$ elevation of surface in a surge tank above reservoir static surface level (chapter 3)

$Z_{\text {sw }} \quad$ elevation above a datum of a suction well base (Chapter 6)

$z_{\mathrm{t}} \quad$ the elevation above datum of the centre line of the pipeline at the point of its junction with an air vessel

$Z \quad$ hydraulic impedance (chapter 9)

$Z_{\text {c }} \quad$ characteristic impedance (chapter 9)

$z \quad$ depth of the centroid of a channel cross section (chapter 10)

$\alpha \quad$ real component of $\gamma$ (propagation constant) (chapter 9)

$\alpha \quad$ constant defining nature of a channel cross section (chapter 10)

$\beta \quad$ the product $\frac{C_{\mathrm{d}} A_{\mathrm{v}}}{A_{\mathrm{p}}} \sqrt{ } 2 \mathrm{~g}$ (chapter 2)

$\beta \quad$ imaginary component of $\gamma$ (propagation constant) (chapter 9)

$\gamma \quad$ pump blade angle (chapter 6)

$\gamma \quad$ propagation constant in chapter 9

$\gamma \quad$ ratio of specific heat of gas (chapter 8 )

$\delta \quad$ ratio of channel cross sectional area/surface breadth (chapter 10)

$\Delta x \quad$ distance increment (finite)

$\Delta t \quad$ time increment (finite)

$\Delta V \quad$ volume increment (with subscripts to define which volume change is intended) (chapter 1)

$\Delta p_{\mathrm{i}} \quad$ pressure increment due to momentum change (finite) (chapter 1)

$\Delta h_{\mathrm{i}} \quad$ potential head change: related to $\Delta p_{\mathrm{i}}$ by $\Delta p_{\mathrm{i}}=w \Delta h_{\mathrm{i}}$ (chapter 1)

$\epsilon \quad$ fractional volume of free gas in liquid (chapter 5)

$\epsilon \quad$ ratio of $a_{\mathrm{e}} / a_{\mathrm{e}_{\mathrm{o}}}$ (chapter 9$)$

$\bar{\epsilon} \quad$ steady component of $\epsilon$ (chapter 9) 
$\epsilon^{\prime} \quad$ unsteady component of $\epsilon$ (chapter 9)

$\zeta \quad$ the square root of the head ratio: $\left(\frac{h}{h_{0}}\right)^{0.5}$ (chapter 2)

$\zeta$ the slope of the characteristic line

$\eta \quad$ fractional valve opening: $\frac{a_{v}}{a_{v_{0}}}$ (chapter 2)

$\theta \quad$ angle in Suter presentation of four quadrant pump characteristic $\theta=\tan ^{-1}\left(\begin{array}{ll}\frac{N}{N_{\mathrm{s}}} & \frac{Q_{\mathrm{s}}}{Q}\end{array}\right)$ (chapter 6)

$\lambda$ constant in the characteristic formulation of the waterhammer equations (chapter 4)

$\lambda \quad \alpha \frac{d}{B} \frac{\partial B}{\partial x}$ (chapter 10)

$\mu \quad$ dynamic viscosity of fluid

$\nu \quad$ kinematic viscosity of fluid $=\frac{\mu}{\rho}$

$\begin{array}{ll}\pi & 3.14159\end{array}$

$\rho$ mass density

$\rho \quad$ Allievi characteristic: $\frac{c v_{0}}{2 g h_{0}} \quad$ (chapter 2)

$\tau \quad$ surface tension coefficient in chapter 5

$\tau \quad$ viscous sheer stress in chapter 2 and chapter 10

$\chi \quad$ the compound line produced by the summing of two eagres in the Schnyder - Bergeron method (chapter 2)

$\psi \quad$ the valve characteristic in the Schnyder - Bergeron method (chapter 2)

$\psi \quad$ phase angle (chapter 9)

$\Omega \quad$ angular velocity of pump impeller (chapter 3 and chapter 6)

$\Omega \quad$ angular velocity of the applied head oscillation (chapter 9) 